\title{
Doctoral Program in Education Leadership Redesign: Utilizing a Multicriteria Framework
}

\author{
Miriam D. Ezzani, EdD \\ University of North Texas \\ miriam.ezzani@unt.edu \\ Noelle A. Paufler, PhD \\ University of North Texas \\ noelle.paufler@unt.edu
}

\begin{abstract}
The development of educational leaders, who have a profound influence in shaping a culture of organizational learning; ethical community engagement; advocacy for diversity, equity and inclusion; and theory to practice solutions, is the aim of redesign efforts in one educational leadership (EDLE) program in the United States. These ideas, grounded in a multicriteria framework, are reified in the Carnegie Project on the Education Doctorate's (CPED) Principles and Design Concepts and reinforced by the University Council for Educational Administration (UCEA) criteria. Yet, right from the beginning, faculty struggled with ideological differences and logistical challenges. Without the dean and department chair's collaborative, visionary leadership and support of key faculty, efforts to redesign the program would have been stifled. We argue that the multicriteria framework, underscoring the importance of collaborative leadership, is the cornerstone of the education doctorate program redesign. The article's contributions are intended to inform the planning, implementation, and evaluation of this program redesign and its impact.
\end{abstract}

KEYWORDS: Carnegie Project on the Education Doctorate (CPED), collaborative leadership, educational leadership program redesign, program implementation and evaluation, University Council for Educational Administration (UCEA)

\section{INTRODUCTION}

This article provides the impetus for innovative change in an educational leadership (EDLE) program at a large, researchintensive university, based on a multicriteria framework and evidentiary data demonstrating preliminary successes-despite logistical challenges and ideological differences among faculty. A multicriteria framework based on the University Council for Educational Administration (UCEA, 2012) criteria and the Carnegie Project on the Education Doctorate (CPED) Principles and Design Concepts (CPED, 2009) offered the will and the means for redesign, respectively. The dean of the College of Education, collaboratively with the department chair, assumed a leadership role in challenging faculty in the EDLE Program to strive toward an effective education doctorate program, which would yield exceptional scholar practitioners and national prominence. Due to ideological differences among faculty in the program, structures and supports were leveraged to plan, implement, and evaluate a successful and impactful redesign of the doctoral program in educational leadership.

\section{Background}

In an effort to support students in the EDLE Program, the dean at the time recommended a two-pronged approach - to become institutional members of both CPED and UCEA. In October 2011, the dean submitted a letter of application to UCEA with the prospect of beginning the process for full institutional membership. Upon review by UCEA, the EDLE Program, housed in the Department of Teacher Education and Administration (TE\&A; University of North Texas, 2017a) was deemed not ready for full membership and asked to submit a five-year improvement plan in preparation for future reconsideration.

For the next three years, the EDLE Program, with limited faculty, initially completed a few items on the improvement plan, and several items remained uncompleted while program faculty turned their attention to the master's program with declining enrollment of less than 16 students. After a one-year planning period, the EDLE Program successfully launched an accelerated online master's program which experienced unexpectedly rapid growth in student enrollment, due in large part to its student-centered approach, high quality course design, and targeted marketing plan. The master's program increased in enrollment from 16 students in the first semester to more than 45 students by the end of the year. Currently in its fourth year, the master's program has close to 400 students. The successful redesign of the master's provided a more robust program to prepare educational leaders in the surrounding districts, and the foundation for the doctoral program redesign by aligning the master's degree with EDLE core values and beliefs and the college and university vision and mission. A sequence of aligned graduate
New articles in this journal are licensed under a Creative Commons Attribution 4.0 United States License.

This journal is published by the University Library System of the University of Pittsburgh as part of its D-Scribe Digital Publishing Program and is cosponsored by the University of Pittsburgh Press.

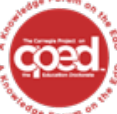

This journal is supported by the Carnegie Project on the Education Doctorate: A Knowledge Forum on the EdD (CPED) cpedinitiative.org 
degree programs in educational leadership was also a requirement for full UCEA membership.

In 2014, the dean urged EDLE faculty to refocus their efforts on the pending tasks on the UCEA improvement plan with careful consideration given to the CPED Principles for Program Design. The faculty aimed to develop a solid working model of the EDLE Program, which included: Master of Education, Doctor of Education, and Doctor of Philosophy in educational leadership (Young, 2006). The will to redesign the doctoral programs to gain full UCEA membership was contingent upon complete engagement, which included attending and serving on committees at the biannual CPED Convenings and the annual UCEA conventions.

Based on the collective learnings from the experiences of other CPED institutions, the EDLE faculty representative facilitated a program retreat in spring 2015 . The EDLE faculty began a self-study to articulate the program's core values and beliefs based on the CPED Principles, and to examine the alignment between graduate courses and the 11 criterion distinguishing programs for full UCEA membership (UCEA, 2012). In a collaborative process, faculty developed the program's core values and beliefs to reflect the needs of the profession, the social justice vision of the university and the department, and CPED Principles. The four core values and beliefs are: (a) lead learning organizations; (b) engage ethically with the community; (c) advocate for diversity, equity, and inclusion; and (d) develop theory to practice solutions (University of North Texas, 2017b). Most of the faculty aimed to make an impact, challenge the traditional model, and increase the effectiveness of its doctoral preparation of educational leaders (Amrein-Beardsley et al., 2012; Cosner, Tozer, Zavitkovsky, \& Whalen, 2015; Perry \& Imig, 2016; Walker, Golde, Jones, Bueschel, \& Hutchings, 2009).

\section{Conceptual Framework}

The program redesign was guided by a multicriteria framework based on the CPED Principles and Design Concepts and reinforced by the UCEA criteria. The collaborative efforts of the dean, department chair, and key program faculty played a pivotal role in the redesign as part of the process for obtaining full UCEA membership. Figure 1 demonstrates the relationship between the above constructs in the Educational Leadership Doctoral Program redesign efforts.

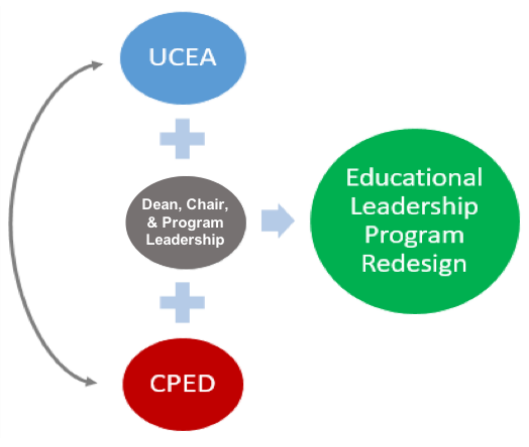

Figure 1. Conceptual Framework for Educational Leadership Doctoral Program Redesign.

To that end, the planning ensued with the alignment of the EDLE Program's core values and beliefs, CPED Principles and
Design Concepts, and UCEA criteria which is provided in Table 1. Specific attention was paid to the first CPED Principle, which "is framed around questions of equity, ethics, and social justice to bring about solutions to complex problems of practice," in the development of the program core values and beliefs (CPED, n.d., para. 7).

\section{PROGRAM REDESIGN}

The CPED Principles served as the underpinnings of the EDLE Program redesign and the conduit toward fulfilling the 11 UCEA criterion and gaining full membership. Components of the redesign include: the cohort model (Barnett, Basom, Yerkes, \& Norris, 2000; Darling-Hammond, LaPointe, Meyerson, Orr, \& Cohen, 2007; Davis \& Darling-Hammond, 2013), degree plans which distinguish between the Education Doctorate $(\mathrm{EdD})$ and Doctor of Philosophy $(\mathrm{PhD})$ in Educational Leadership (Shulman, Golde, Bueschel, \& Garabedian, 2006), blended delivery model, course development and redesign, course sequence, which allows for a scaffolded approach to the dissertation writing process (CPED, 2017; Peterson, 2017). In conjunction with the planning of the redesign was the creation of a Superintendent Advisory Council (one of the UCEA criterion), comprised of 20 superintendents from nearby districts, who served as partners and collaborators in the redesign process and continue to provide feedback on program design, implementation, and evaluation of outcomes (e.g. student recruitment, retention, and ontime graduation; Orr, 2011). Thus, since 2015 the faculty have intentionally worked to implement the program redesign through a collaborative effort with informal (key faculty) and formal leadership structures (dean and chair), respectively (Kezar \& Lester, 2011). As part of the cohort delivery model, as of 2016 , four cohorts with a total of 65 students have begun, with the first cohort anticipated to graduate in 2019. Ongoing efforts in semiannual faculty retreats led by faculty continue to evaluate the program based on desired outcomes and to refine the program to address student needs (Perry, 2014). The impact of this program is being measured based on student recruitment, retention, and on-time graduation.

\section{CPED Principles}

The six CPED Principles informing the redesign process of the education doctorate reflect the profile of the scholarly practitioner. The first principle "is framed around questions of equity, ethics, and social justice to bring about solutions to complex problems of practice" (CPED, n.d., para. 7). This principle is reflected in the Department of TE\&A vision, the EDLE Program's core values and beliefs, and in the course development and redesign. Specifically, the Department of TE\&A vision states: "We aspire to be internationally recognized for developing visionary educators who provide leadership, promote social justice, and effectively educate learners" (UNT, 2017a, para. 3). The second, third, and fourth EDLE Program core values and beliefs (i.e., engaging ethically with the community; advocating for diversity, equity, and inclusion; and developing theory to practice solutions) directly reflect this principle and are reinforced in the content of the courses taught, specifically focused on issues of ethics and social justice. Not everyone was on board with a social justice emphasis, however. A few expressed a belief that social justice was "old school." Equity minded faculty leveraged the university and departmental vision to reinforce the 
Table 1. Alignment of the Program's Core Values and Beliefs with CPED Principles and UCEA Criteria

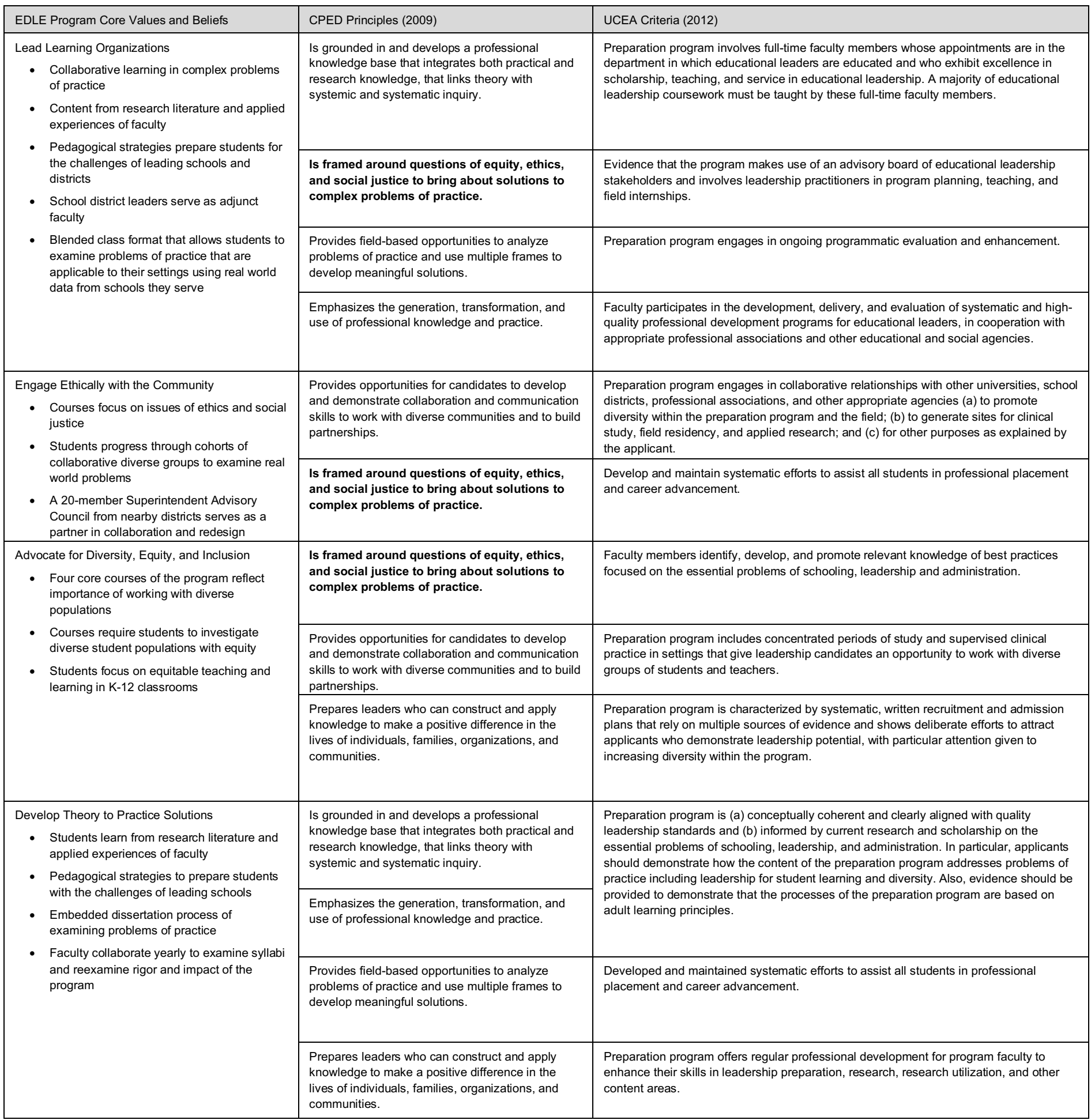


need for the inclusion of social justice in alignment to this CPED Principle. The first core value and belief (i.e., leading learning organizations) also indirectly reflects this principle by emphasizing the need for collaborative learning in solving complex problems of practice.

A scholarly practitioner is prepared to lead in complex settings which include urban, rural, and suburban districts with changing demographics. Education doctoral programs that reflect the second principle "prepare leaders who can construct and apply knowledge to make a positive difference in the lives of individuals" (CPED, n.d., para. 7). This principle is evident in a number of courses in the program. Students learn content from the research literature and through the applied experiences of faculty (all of whom have experience as former practitioners) and sitting superintendents who serve as adjunct faculty. Additionally, pedagogical strategies such as fieldwork, teaching strategies, hands-on learning, and data-driven decision making prepare students to grapple with the challenges of leading schools and districts with rapidly changing demographics. Faculty again were divided on the importance of emphasizing administrative and management courses at the expense of courses that would prepare students to better serve the needs of diverse populations. Faculty who desired an emphasis on the latter proposed the removal of two business courses and the addition of a course in ethics and social justice as well as a policy course. As a result of the philosophical divide, faculty compromised by removing one of the two business courses and combining the ethics, social justice, and policy into one new course. As a result, graduates are better prepared to serve in leadership positions, in terms of how they engage with the educators and students in their schools and with the community at large.

As a catalyst to actualize the third CPED Principle, the program "provides opportunities for candidates to develop and demonstrate collaboration and communication skills to work with diverse communities and to build partnerships" (CPED, n.d., para. 7). Faculty deliberately redesigned the program to ensure students progressed through their coursework in cohorts. Cohorts include culturally and geographically diverse groups of students with varied personal and professional experiences. Courses are designed to allow them to collaborate and communicate with each other on projects that examine real problems of practice in settings that involve relationship building and partnerships with their community stakeholders. As one of the first changes made in the program design, faculty proposed that the cultural foundations course be a required rather than an elective course on the degree plan. As was later seen with the addition of the ethics, social justice, and policy course, this change prompted resistance. With this change, the four core courses, which includes the cultural foundation course, on the degree plan reflect the importance of collaboration and communication skills, especially in working with diverse communities.

EDLE students are "provide[d] field-based opportunities to analyze problems of practice and use multiple frames to develop meaningful solutions" (CPED, n.d., para. 7). This fourth CPED Principle challenges students to apply course learning in context, examine local problems through multiple perspectives, and develop solutions that make a difference in the lives of those they serve. In this program, faculty designed course content and assignments which require students to investigate situations centered on underserved and marginalized student populations with an equity minded focus. Students are encouraged to elicit the perspectives of district administrators, school leaders, teachers, parents, and students to empower them into action. Faculty deliberately redesigned courses to shift from a teacher-centered to studentcentered approach by delivering courses in a blended format (i.e., face-to-face and online) which respects students' professional commitments and allows them to examine problems of practice that are applicable to their settings. This means that students examined problems in small groups using real data from the schools and districts in which they serve.

Students graduating with an education doctorate are expected to demonstrate the EDLE Program's fourth core value and belief of "developing theory to practice solutions." Commensurate with the fifth CPED Principle, students need to be "grounded in and develop(s) a professional knowledge base that integrates both practical and research knowledge, that links theory with systemic and systematic inquiry" (CPED, n.d., para. 7). As part of the redesign, faculty attempted to reach consensus on the sequence of courses. Some of the faculty believed that the core courses, which were closely aligned with the program's core values and beliefs, should be the students' first learning experience in the program. Other faculty believed that the courses leading to superintendent certification should be first in the course sequence to serve as a marketing tool to attract doctoral students. Based on the challenges of recruitment at the time, faculty decided to organize the courses beginning with the superintendent certification. After two years of implementing the redesigned course sequence and with the first cohort nearing the completion of their coursework, faculty are reevaluating several specific aspects of student experiences based on formative data collection occurring in formal and informal settings (small group discussion, whole group discussions during class, individual communications, and student evaluations). For example, the students indicated that the placement of core courses that expose students to the theoretical underpinnings of educational leadership should occur in year one. In the spirit of continuous improvement, faculty have changed the course sequence for the incoming fifth cohort. It was discovered that some students completed the superintendent certification courses and then dropped out of the doctoral program. This fifth cohort and those thereafter will be introduced to theoretical and research methods courses during their first year and the superintendency courses will be sprinkled in throughout the program and offered online as a value added to students seeking district positions in the future. Introducing core courses in year one will help students engage in systematic inquiry and make theory to practice connections earlier in their doctoral program. As another example, the revised course sequence now involves writing chapters one and two of the dissertation in different core courses during the same semester. For the working professional, this maximizes the opportunity to read, think, and write critically about a problem of practice in the context of the existing literature.

Scholarly practitioners should be prepared to actualize their learning. The sixth CPED Principle "emphasizes the generation, transformation, and use of professional knowledge and practice" (CPED, n.d., para. 7). The opportunities for students to address problems of practice in their various courses gives them the confidence to focus on a dissertation topic that has the potential to effect positive change in their setting and contribute meaningfully to the field. In order to improve students' experiences, faculty were tasked with evaluating and increasing the level of rigor across courses, specifically to ensure that students engage in scholarly reading and writing. A good number of courses already include the 
exposure to scholarship that prepares students to produce a highquality dissertation in practice. Annual faculty retreats provide opportunities to collaboratively examine course syllabi and continue to identify ways to not only increase rigor but also generative impact. Having already redesigned a critical mass of courses, faculty continue to develop and revise courses to assure relevance and incorporation of the core values and beliefs.

The faculty relied on the CPED Principles to develop the program's core values and beliefs; to design courses centered around ethics, equity, and social justice; and to help graduates lead in complex settings, develop skills of collaboration and communication to work in diverse communities, apply course learning to analyze and solve problems of practice, and integrate practice and research knowledge to engage in systematic inquiry. Whereas the CPED Principles guide the professional doctorate in education, the CPED Design Concepts define program components that support the development of scholarly practitioners.

\section{CPED Design Concepts}

The six CPED Design Concepts determine program components that foster the development of effective educational leaders. The Design Concepts, in their totality, are intended to scaffold thinking and learning in preparation for the final outcome, a dissertation examining a problem of practice. At the forefront, EDLE faculty in this program sought to increase student retention and ontime graduation for students who are working professionals, while meeting their ethical obligation to produce extraordinary educational leaders. By embedding $60 \%$ of the dissertation writing process in the coursework, students are challenged to think about the end goal of their program in year one. The design concepts support students in achieving this goal.

In the first three Design Concepts, students prepare by gathering the knowledge and skills to engage in dissertation research. The first CPED Design Concept requires "Scholarly Practitioner[s] [to] blend practical wisdom with professional skills and knowledge to name, frame, and solve problems of practice" (CPED, n.d., para. 9). In their coursework, students select and investigate concerns centered on issues of equity and social justice in the literature, and subsequently, identify the gap in existing literature. They learn how to identify a problem, structure the purpose of a study, and frame questions by which to examine the problem. Per the second Design Concept, "Signature Pedagogy is a set of practices used to prepare scholarly practitioners for all aspects of their professional work" (CPED, n.d., para. 9). Students are focused on the work of teaching and learning which is happening in the $\mathrm{K}-12$ classroom from an equity lens. Faculty help students develop a mindset that anchors them to engage in "a set of practices" that keep $\mathrm{K}-12$ students at the forefront through culturally relevant curriculum and pedagogical strategies. By means of the third Design Concept, "Inquiry as Practice is the process of posing significant questions that focus on complex problems of practice. By using various research, theories, and professional wisdom, scholarly practitioners design innovative solutions to address the problems of practice" (CPED, n.d., para. 9). As an avenue to engage students in inquiry, they develop quantitative and qualitative research skills throughout their coursework. Faculty agree that this component is still problematic in that students learn research skills from faculty in other departments who do not have an educational leadership background. This disconnects research methodology from their problem of practice.
For the most part, the program is designed to embed the dissertation process through the first three Design Concepts.

The latter three Design Concepts help students fulfill the requirements of the dissertation by conducting their research study. In the fourth Design Concept, "Laboratories of Practice are settings where theory and practice inform and enrich each other" (CPED, n.d., para. 9). Students bring their expertise to bear on a problem of practice in their setting. This design concept is established in the program by fostering camaraderie between faculty and students through semiannual small group advisement. This generates opportunities for students who work in similar settings to more easily share and collaborate as teams in data collection and analysis. In tandem and as part of the fifth Design Concept, a "Problem of Practice is a persistent, contextualized, and specific issue embedded in the work of a professional practitioners; addressing the issue has the potential to result in improved understanding, experience, and outcomes" (CPED, n.d., para. 9). Students better understand their problem of practice and discover solutions that can inform change to positively impact K-12 educators and students. Finally, the sixth Design Concept encapsulates the "Dissertation in Practice [that] is a scholarly endeavor that impacts a complex problem of practice" (CPED, n.d., para. 9). A scholarly practitioner is capable of developing theory to practice solutions (the program's fourth core value). The faculty believe that the end goal of a professional doctorate in education is to serve their local communities by providing them with thoughtful and caring educational leaders. These six Design Concepts provide the foundation for the Carnegieinfluenced redesign which made the program worthy of full institutional membership in UCEA. It is important to note that due to the ideological differences among faculty, the fourth core value and belief, theory to practice solutions, is the only value that does not always embed the first CPED Principle framed around questions of equity, ethics, and social justice to bring about solutions to complex problems of practice.

\section{DISCUSSION AND RECOMMENDATIONS}

Initially in 2011 and at the behest of the then-current dean, the EDLE faculty were charged with undergoing a Carnegie-influenced program redesign for the purpose of improving the preparation of educational leaders and to merit full institutional membership in UCEA. The dean considered the accomplishment of these tasks as a marker of success not only for the program and department but for the college and university. Over the past six years, EDLE faculty partnered with district superintendents to conceptualize, develop, implement and evaluate a Carnegie-influenced redesign plan. Right from the beginning, faculty struggled with ideological differences and logistical challenges. To some extent, changing what had been done previously was interpreted as delegitimizing the goals, values, and efforts of long-standing faculty as well as destabilizing the existing structure. Without the vision, support, and collaborative leadership of the dean and the department chair, and the informal leadership of faculty, efforts to redesign the program would have been squelched (Lester, 2009).

In retrospect, existing and new faculty moved the work forward by distinguishing between the EdD and PhD (Shulman, Golde, Bueschel, \& Garabedian, 2006) in terms of number of credit hours required and course content, introducing a blended delivery format in a cohort model, developing and redesigning courses and the course sequence, and scaffolding the approach to the dissertation writing 
process. All of these efforts combined were introduced in the program's marketing strategy to recruit high-quality working professionals committed to earning an education doctorate. Partnerships with district superintendents were a conduit to attracting cohorts of students, often from the same district, who currently hold or seek to advance in leadership positions to allow them to make substantive change in their organization. This model promotes student retention by fostering professional and collegial support as they advance through the program. Although the first cohort of students will not graduate until 2019, preliminary recruitment and retention data have been used to evaluate the program's impact and suggest positive outcomes thus far.

The outcomes of the Carnegie-influenced program redesign were recognized early on through full institutional membership in UCEA. Other measures of success include increased interest in the program and higher rates of retention, which all indicate the potential for more students to graduate on time. As part of recruitment efforts, faculty held informational sessions at district offices and invited each district superintendent to attend. As a result of strategic marketing efforts, three cohorts of 21,14 , and eight students, respectively, were successfully recruited across different satellite sites in the first year (2016). An additional cohort of 20 students started at one of the sites in 2017, and recruitment and admission efforts are underway for the fifth and sixth cohorts at two sites to begin in fall 2018. More than 70 prospective students have attended informational sessions for this admission cycle. This reflects a significant increase in interest over previous years, due primarily to stronger district partnerships and word of mouth. Thus far in terms of retention, at least $80 \%$ of the students in each existing cohort have followed the degree plan and course sequence. The first three cohorts of 45 students are currently completing their final courses and are expected to graduate in 2019.

Based on lessons learned, the impetus for the Carnegieinfluenced program redesign is anchored in the fact that professional organizations (CPED and UCEA) provide models for best practices in educational leadership preparation. First and foremost, the dean's commitment to and EDLE faculty involvement in the semiannual CPED Convenings were critical. Candid discussions with other CPED institutions provided faculty with the strengths and challenges of redesign. Second, faculty engagement through full-day retreats and monthly meetings provided the time for strategic planning, thoughtful implementation, evaluation and refinement, and problem solving. These annual and monthly events ensure continuous improvement focused on student success in the program and a direct impact on the K-12 communities they serve. Third, faculty reflected on the progress of the program redesign, in part by recently preparing the CPED Member Program Report and engaging in the UCEA INSPIRE surveys (UCEA, 2013). Recognizing the importance of collecting data to evaluate program outcomes, faculty are currently developing a study to examine the experiences of students in the program before the redesign and those of students admitted in the UCEA/CPED-influenced cohort model. EDLE faculty believe that the multicriteria framework, which inspired intense involvement and program membership in CPED and UCEA, respectively, have significantly improved the reputation of the program and exponentially increased interest in it. Just as significant is the collaborative, visionary leadership of the dean and the department chair in the success of the redesign (Lester, 2009). The program is now better situated to influence educational leadership preparation in the field at local, state, and national levels.

\section{REFERENCES}

Amrein-Beardsley, A., Zambo, D., Moore, D. W., Buss, R. R., Perry, N. J., Painter, S. R.,...Puckett, K. S. (2012). Graduates respond to an innovative educational doctorate program. Journal of Research on Leadership Education, 7(1), 98-122.

Barnett, B. G., Basom, M. R., Yerkes, D. M., \& Norris, C. J. (2000). Cohorts in educational leadership programs: Benefits, difficulties, and the potential for developing school leaders. Educational Administration Quarterly, 36, 255-292.

Carnegie Project on the Education Doctorate (CPED). (n.d.). Guiding principles for program design. Retrieved from http://www.cpedinitiative.org/page/AboutUs

Carnegie Project on the Education Doctorate (CPED). (2009, October). Development of the CPED working principles. Retrieved from http://www.cpedinitiative.org/default.asp?page=HistoryPrinciples

Carnegie Project on the Education Doctorate (CPED). Carnegie Project on the Education Doctorate for member institutions and faculty page. Retrieved from www.cpedinitative.org

Cosner, S., Tozer, S. Zavitkovsky, P., \& Whalen, S. P. (2015). Cultivating exemplary school leadership preparation at a research intensive university. Journal of Research on Leadership Education, 10(1), 11-38.

Darling-Hammond, L., LaPointe, M., Meyerson, D., Orr, M. T., \& Cohen, C. (2007). Preparing school leaders for a changing world: Lessons from exemplary leadership development programs. Stanford, CA: Stanford University.

Davis, S., \& Darling-Hammond, L. (2012). Innovative principal preparation programs: What works and how we know. Planning and Changing, 43(12), 25-45.

Kezar, A., \& Lester, J. (2011). Enhancing campus capacity for leadership: An examination of grassroots leaders in higher education. Stanford, CA: Stanford University Press.

Lester, J. (2009). Organizing higher education for collaboration: A guide for campus leaders. San Francisco, CA: John Wiley \& Sons.

Orr, M. T. (2011). Pipeline to preparation to advancement: Graduates experiences in, through, and beyond leadership preparation. Educational Administration Quarterly, 47, 114-172.

Perry, J. (2014). Changing schools of education through grassroots faculty-led change. Innovative Higher Education, 39(2), 155-168.

Perry, J. A., \& Imig, D. G. (2016). What do we mean by impact? Impacting Education: Journal on Transforming Education, 1(1), 1-3. Retrieved from https://impactinged.pitt.edu/ojs/index.php/ImpactingEd/article/view/26

Peterson, D. S. (2017). Preparing Scholarly Practitioners: Redesigning the EdD to Reflect CPED Principles. Impacting Education: Journal on Transforming Education, 2(1), 1-8.

Shulman, L. S., Golde, C. M., Bueschel, A. C., \& Garabedian, K. J. (2006) Reclaiming education's doctorates: A critique and a proposal. Educational Researcher, 35(3), 25-32. Retrieved from http://journals.sagepub.com/doi/abs/10.3102/0013189X035003025

University Council for Educational Administration (UCEA). (2013). Center for the Evaluation of Educational Leadership Preparation and Practice. Charlottesville, VA: Author. Retrieved from http://edleaderprepucea.squarespace.com/survey-suite-overview/

University Council for Educational Administration (UCEA). (2012). Institutional and program quality criteria: Guidance for master's and doctoral programs in educational leadership. Retrieved from http://3fl71l2qoj4l3y6ep2tqpwra.wpengine.netdna-cdn.com/wpcontent/uploads/2014/07/UCEAProgramCriteria.pdf

University of North Texas. (2017a). Department of Teacher Education and Administration. Retrieved from https://www.coe.unt.edu/teachereducation-and-administration

University of North Texas. (2017b). Donald A. Buchholz Doctoral Program in Educational Leadership. Retrieved from

https://www.coe.unt.edu/teacher-education-and-administration/graduateprograms/educational-leadership-doctoral-programs

Walker, G. E., Golde, C. M., Jones, L., Bueschel, A. C., \& Hutchings, P. (2009). The formation of scholars: Rethinking doctoral education for the twenty-first century (Vol. 11). San Francisco, CA: John Wiley \& Sons.

Young, M. (2006). The MEd, EdD and PhD in Educational Leadership. UCEA Review, 45(2), 6-9. 